\title{
PENGARUH CUSTOMER SATISFACTION DAN PERCEIVED VALUE TERHADAP SWITCHING BARRIERS DAN CUSTOMER LOYALTY Gunarso Wiwoho
}

\author{
Email: gunarsowiwoho@yahoo.com \\ Sekolah Tinggi Ilmu Ekonomi Putra Bangsa, Kebumen
}

\begin{abstract}
ABSTRAK
Penelitian ini bertujuan untuk menguji dan menganalisis pengaruh dari customer satisfaction dan perceived value terhadap customer loyalty melalui switching barrier sebagai variabel intervening. Pengumpulan data dilakukan dengan kuesioner. Dengan menggunakan teknik non probability sampling, penelitian dan diterapkan teknik sampling purposive, penelitian ini mengami sampel 100 responden konsumen Bakery Kebumen sebagai konsumen akhir dengan waktu pembelian minimal dua kali dalam satu minggu. Pengaruh customer satisfaction terhadap switching barrier menunjukkan bahwa customer satisfaction tidak signifikan terhadap switching barrier. Pengaruh perceived value terhadap switching barrier menunjukkan bahwa perceived value tidak berpengaruh signifikan terhadap switching barriers. Pengaruh customer satisfaction terhadap customer loyalty menunjukkan bahwa customer satisfaction berpengaruh signifikan terhadap customer loyalty. Pengaruh perceived value terhadap customer loyalty menunjukkan bahwa perceived value tidak berpengaruh signifikan terhadap customer loyalty. Pengaruh switching barrier terhadap customer loyalty menunjukkan bahwa switching barrier berpengaruh signifikan terhadap customer loyalty. Switching barrier dapat dijelaskan oleh customer satisfaction dan perceived value sebesar 3,1\% sedangkan sisanya 96,9\% dipengaruhi oleh variabel lain. Customer loyalty dapat di jelaskan oleh customer satisfaction, perceived value dan switching barriers sebesar 16,9\% sedangkan $83,1 \%$ dipengaruhi oleh variabel lain.
\end{abstract}

Kata Kunci: customer satisfaction, perceived value, switching barrier, customer loyalty

\section{PENDAHULUAN}

Sejak jaman dahulu warga Romawi mencintai makanan yang dipanggang, sehingga sekitar 300 SM seiring dengan ketenaran seni pemanggang, pekerjaan memanggang menjadi profesi yang terhormat dikalangan warga Romawi. Istilah bakery digunakan untuk menyebut panganan berupa roti, cake, pastry, dan sejenisnya yang dimasak dengan cara dipanggang. Bakery memiliki keistimewaan dalam hal aroma yang sangat lezat dan dapat tercium dari jarak yang relative jauh. Meskipun sebagian ada yang dimasak dengan digoreng. Untuk bahan dari bakery selalu sama seperti tepung terigu, lemak, gula, telur, garam dan air susu.

Roti adalah makanan berbahan dasar utama tepung terigu dan air, yang difermentasikan dengan ragi, tetapi ada juga yang tidak menggunakan ragi. Namun kemajuan teknologi manusia membuat roti diolah dengan berbagai bahan seperti garam, minyak, mentega, ataupun telur untuk menambahkan kadar protein didalamnya sehingga didapat tekstur dan rasa tertentu. Roti termasuk makanan pokok dibanyak negara Barat. Roti biasanya dijual dalam bentuk sudah diiris dan dalam kondisi fresh yang dikemas rapi dalam plastik.

Sedangkan untuk di Indonesia sendiri roti telah dikenal sejak jaman Belanda sekitar tahun 1930, budaya makan roti biasa dilakukan orang-orang Barat dan mulai diperkenalkan oleh orang pribumi dengan cara diperjual- belikan. Saat ini roti memiliki banyak modifikasi dari berbagai negara yang masuk ke Indonesia dengan rasa dan teksture yang bervariasi, sehingga banyak gerai bakery yang bermunculan di Indonesia. 
Untuk gerai bakery di wilayah Kebumen cukup banyak yaitu Jempol, Latulip, Purimas dan Banana dan lain sebagainya. Namun dari sekian banyak gerai yang berada di Kebumen, Banana Bakery lah yang sampai saat ini masih eksis dikalangan warga Kebumen, karena mereka beranggapan bahwa Banana Bakery Kebumen memiliki value lebih dibandingkan dengan gerai bakery lain di Kebumen, yakni memiliki keunggulan dalam hal kualitas produknya. Selain itu banyak pula yang menganggap jika mereka membeli produk dari roti Banana Bakery maka kedudukan status sosial mereka akan berada pada kelas menengah ke atas.

Tentunya Banana Bakery tidak mudah untuk mempertahankan eksistensinya apalagi dengan banyaknya persaingan yang bermunculan. Oleh sebab itu, Banana Bakery harus membuat konsumen puas, jika konsumen puas tentunya kemungkinan untuk berpindah ke produk lain sangat kecil sehingga konsumen akan loyal. Menurut Lovelock et al. (2005), hubungan antara kepuasan dengan loyalitas dibagi menjadi tiga zona. Pertama zone of defection, kedua zone of indifference dan ketiga zone of affection. Menurut Micu (2013), kepuasan konsumen (customer satisfaction) adalah perasaan senang atau kecewa seseorang yang muncul setelah membandingkan antara persepsi/kesannya terhadap kinerja (hasil) suatu produk dan harapan-harapannya. Selain itu perlu adanya persepsi nilai dari konsumen terhadap roti dari produk Banana Bakery tersebut, yang dimana akan menimbulkan persepsi jika membeli dan mengonsumsi roti tersebut akan memberikan nilai lebih terhadap konsumen. Menurut Khotler dan Keller (2015:14) Perceived value adalah cerminan sejumlah manfaat, baik yang berwujud maupun yang tidak berwujud dan biaya yang dipersepsikan oleh pelanggan.

Apabila konsumen enggan untuk berpindah ke produk lain dan memilih untuk tetap membeli dan mengonsumsi roti dari Banana Bakery, maka konsumen tersebut sudah dikatakan loyal akan produk roti tersebut. Karena saat mereka mencoba untuk berpindah ke produk roti lain maka akan menimbulkan ketidakpuasan terhadap produk lain yang mereka coba. Menurut Fornell dalam Lupiyoadi (2013:237), hambatan beralih (switching barriers) mengacu pada tingkat kesulitan untuk pindah atau beralih ke penyedia barang atau jasa lain yang dihadapi pelanggan yang tidak puas dengan jasa yang diterima atau mengacu pada kendala finansial, sosial, dan psikologis yang dirasakan seorang pelanggan ketika pindah atau beralih ke produk dan penyedia jasa baru. Menurut Jones, et. al., (2000), switching barrier memiliki beberapa faktor pendukung, yaitu switching cost, daya pikat alternatif ( alternative attractiveness ) dan hubungan interpersonal (interpersonal relationship ). Sedangkan menurut Lovelock dan Wright (2005) mengungkapkan loyalitas sebagai keputusan pelanggan untuk terus berlangganan pada sebuah perusahaan tertentu dalam jangka panjang, dengan membeli dan menggunakan barang dan jasa secara berulang-ulang, dan dengan suka rela merekomendasikan produk perusahaan tersebut kepada rekan-rekannya.

Mengingat pentingnya hambatan beralih sehingga dapat menyebabkan konsumen loyal, penelitian ini berusaha untuk mengkaji faktor-faktor seperti customer satisfaction dan perceived value melalui switching barriers sehingga mempengaruhi customer loyalty. Pertimbangan pemilihan produk roti Banana bakery sebab produk roti Banana Bakery ini menjadi salah satu gerai bakery di Kebumen yang terkenal dan memiliki banyak peminat.

Berdasarkan uraian tersebut maka penulis tertarik untuk melakukan penelitian dengan judul "Pengaruh Customer Satisfaction dan Perceived Value terhadap Switching Barrier dan Customer Loyalty" Tujuan Penelitian

Adapun tujuan pelaksanaan penelitian ini adalah: 
1. Untuk mengetahui pengaruh Costumer Satisfaction terhadap Switching Barrier pada konsumen Bakery.

2. Untuk mengetahui pengaruh Perceived Value terhadap Switching Barrier pada konsumen Bakery.

3. Untuk mengetahui pengaruh Customer Satisfaction terhadap Customer Loyalty pada konsumen Bakery.

4. Untuk mengetahui pengaruh Perceived Value terhadap Customer Loyalty pada konsumen Bakery.

5. Untuk mengetahui pengaruh antara

Switching Barrier terhadap Customer

Loyalty pada konsumen Bakery.

6.

\section{KAJIAN TEORI \\ Customer Satisfaction}

Tjiptono (2008:24) mendefinisikan kepuasan konsumen adalah perbandingan persepsi konsumen terhadap suatu produk dengan harapan dan kinerja aktual produk yang dirasakan.

Menurut Hawkins dan Lonney dikutip (dalam Tjiptono 2004:101), Customer Satisfaction pada penelitian ini dapat di ukur dengan indikator:

1.Kesesuaian harapan.

2.Minat berkunjung kembali.

3.Kesediaan merekomendasikan.

\section{Perceived Value}

Syamsiah (2009) perceived value merupakan akibat atau keuntungan keuntungan yang diterima pelanggan dalam kaitannya dengan total biaya (termasuk didalamnya adalah harga yang dibayarkan di tambah biaya - biaya lain terkait dengan pembelian)

Menurut Mohammad (2012), perceived value pada penelitian ini dapat diukur dengan indikator :

1.Kelayakan.

2. Harga yang pantas.

3. Menawarkan nilai yang baik.

4. Kesesuaian harga dengan produk.
Switching Barrier

Menurut Fornell (dalam Lupiyoadi 2013:237), hambatan beralih (switching barrier) mengacu pada tingkat kesulitan untuk pindah atau beralih ke penyedia barang atau jasa lain yang dihadapi pelanggan yang tidak puas dengan jasa atau produk yang diterima atau mengacu pada kendala finansial, sosial, dan psikologis yang dirasakan seorang pelanggan ketika pindah atau beralih ke produk atau penyedia jasa baru.

Menurut Danes, Nasab dan Ling (2012), Switching Barrier pada penelitian ini dapat diukur dengan indikator :

1.Kerugian yang timbul jika berpindah ke produk lain.

2. Berpindah ke produk lain kurang efisien.

3. Kemungkinan pindah ada, apabila produk lain memiliki fitur yang lebih baik.

\section{Costumer Loyalty}

Lovelock dan Wright (2005) mengungkapkan loyalitas sebagai keputusan pelanggan untuk terus berlangganan pada sebuah perusahaan tertentu dalam jangka panjang, dengan membeli dan menggunakan barang dan jasa secara berulang-ulang, dan dengan suka rela merekomendasikan produk perusahaan tersebut kepada rekan-rekannya.

Menurut Menurut Hidayat (2009:103), Customer Loyalty pada penelitian ini di batasi pada:

1. Trust, merupakan tanggapan kepercayaan konsumen terhadap pasar.

2. Emotion commitment, merupakan komitmen psikologi konsumen terhadap pasar.

3. Switching cost, merupakan tanggapan konsumen tentang beban yang diterima ketika terjadi perubahan.

4. Word of mouth, merupakan perilaku publisitas yang dilakukan konsumen terhadap pasar.

\section{MODEL EMPIRIS}

Berdasarkan landasan teori diaas, dapat dikembangkan sebuah kerangka 
pemikiran teoritis yang dapat dilihat pada gambar berikut ini:

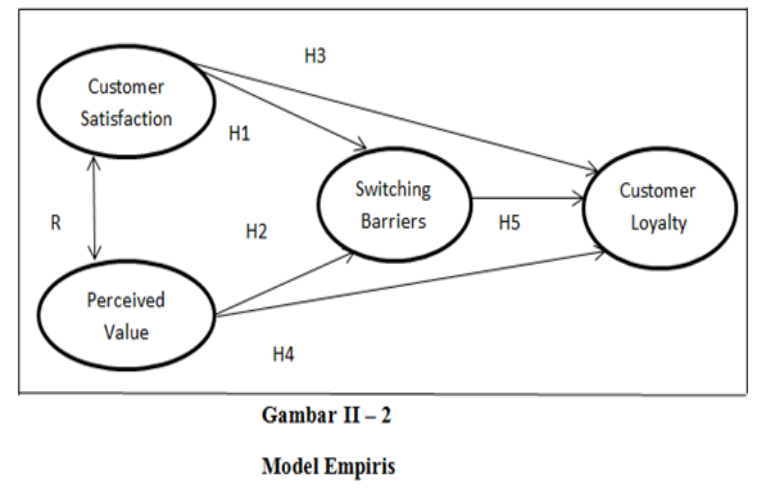

\section{Hipotesis}

H1: Di duga customer satisfaction berpengaruh terhadap switching barriers pada konsumen Banana Bakery Kebumen

$\mathrm{H} 2$ : Di duga perceived value berpengaruh terhadap switching barriers pada konsumen Banana Bakery Kebumen

H3: Di duga customer satisfaction berpengaruh terhadap customer loyalty pada konsumen Banana Bakery Kebumen

H4: Di duga perceived value berpengaruh terhadap customer loyalty pada konsumen Banana Bakery Kebumen

H5: Di duga switching barriers berpegaruh terhadap customer loyalty pada konsumen Banana Bakery Kebumen

\section{METODE}

Rancangan penelitian ini menggunakan pengujian hipotesis dan penelitian ini menggunakan jenis penelitian kuantitatif. Populasi pada penelitian ini adalah selurh konsumen banana bakery kebumen dan metode pengambilan sampel menggunakan teknik non probaility sampling yaitu penentuan sampel dengan menggunakan pertimbangan tertentu dengan jumlah 100 konsumen.

Teknik pengumpulan data yang dilakukan dengan cara: (1) menyebar kuesioner langsung; (2) wawancara; (3) studi pustaka. Instrument dalam penelitian dilakukan dengan ditunjukkan ntuk memperoleh jawaban dari responden. Alat bantu pengolahan data mengguakan SPSS versifor windows versi 22.0. Teknik analisis yang digunakan dengan dua cara yaitu analisis deskripti dan analisis statistika. Analisis data secara statistika meliputi: (1) Uji validitas dan reabilitas; (2) Uji asumsi Klasik; (3) Uji hipotesis; (4) Uji Parsial /Uji T; (5) Analisis Jalur.

\section{Hasil Uji Validitas}

Customer Satisfaction

\begin{tabular}{|c|c|c|c|c|c|}
\hline Variabel & Butir & ritug & $\mathrm{r}_{\text {tabel }}$ & Signifikansi & Keterangan \\
\hline Customer & 1 & 0,928 & 0,1966 & 0,000 & Valid \\
\hline Customer & 2 & 0,942 & 0,1966 & 0,000 & Valid \\
\hline Satisfaction & 3 & 0,759 & 0,1966 & 0,000 & Valid \\
\hline
\end{tabular}

sebesar $0,000<0,05$ maka semua item pernyataan pada kuesioner variabel costumer satisfaction (X1) dinyatakan valid.

Perceive Value

\begin{tabular}{|c|c|c|c|c|c|}
\hline Vanabel & Butir & $T_{\text {mex }}$ & $\mathrm{T}_{\text {sase: }}$ & Signifitiansi & Keterangan \\
\hline $\begin{array}{c}\text { Percrived } \\
\text { Value }\end{array}$ & $\begin{array}{l}1 \\
2 \\
3 \\
4 \\
\end{array}$ & $\begin{array}{l}0,573 \\
0,776 \\
0,742 \\
0,693 \\
\end{array}$ & $\begin{array}{l}0,1966 \\
0,1966 \\
0,1966 \\
0,1966\end{array}$ & $\begin{array}{l}0,000 \\
0,000 \\
0,000 \\
0,000\end{array}$ & $\begin{array}{l}\text { Valid } \\
\text { Valid } \\
\text { Valid } \\
\text { Valid } \\
\end{array}$ \\
\hline
\end{tabular}

Berdasarkan tabel IV- 7 diatas diketahui bahwa $r$ hitung lebih besar dari $r$ tabel (0.1966) dengan nilai signifikansi sebesar $0,000<0,05$ maka semua item pernyataan pada kuesioner variabel perceived value ( X2 ) dinyatakan valid.

Switching Barrier

\begin{tabular}{|c|c|c|c|c|c|}
\hline Vaniabel & Butir & $\mathrm{F}_{\text {Yetar }}$ & $\mathrm{r}_{\text {tabet }}$ & Signifileansi & Keteran \\
\hline Switching & $\mathrm{T}$ & 0,807 & 0,1966 & 0,000 & Valid \\
\hline & 2 & 0,845 & 0,1966 & 0,000 & Valid \\
\hline Barrier & 3 & 0,631 & 0,1966 & 0,000 & Valid \\
\hline
\end{tabular}

Sweber:; Data Primer, 20181

Berdasarkan tabel IV- 8 diatas diketahui bahwa $r$ hitung lebih besar dari $r$ tabel (0.1966) dengan nilai signifikansi sebesar $0,000<0,05$ maka semua item pernyataan pada kuesioner variabel Switching Barriers ( Y1 ) dinyatakan valid. 
Customer Loyaly

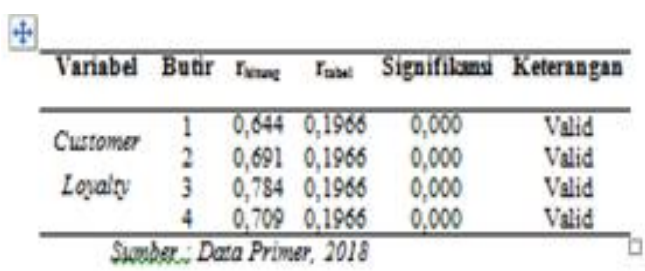

Berdasarkan tabel IV- 9 diatas diketahui bahwa $r$ hitung lebih besar dari $r$ tabel (0.1966) dengan nilai signifikansi sebesar $0,000<0,05$ maka semua item pernyataan pada kuesioner variabel Customer Loyalty ( Y2 ) dinyatakan valid.

\section{Hasil Uji Reabilitas}

\begin{tabular}{lccl} 
Variabel & rleritis & $\begin{array}{c}\text { Cronbacth's } \\
\text { alpha }\end{array}$ & Keterangan \\
\hline Customer Sariffaction & 0,60 & 0,851 & Reliabel \\
Perceived Voive & 0,60 & 0,690 & Reliabel \\
Switching Bariars & 0,60 & 0,646 & Reliabel \\
Customer Loyaiy & 0,60 & 0,664 & Reliabel \\
\hline
\end{tabular}

Sumber:Data Primer, 2018

Dari tabel IV-10 diatas, menunjukan bahwa hasil uji reliabilitas terhadap 4 variabel menunjukan hasil reliabel, karena masing-masing variabel memiliki cronbach'salpha lebih dari 0,6, maka semua variabel pada pernyataan tersebut reliabel.

\section{Uji Asumsi Klasik}

\section{Uji Multikolinieritas}

Berdasarkan tabel IV-11 diatas, diketahui bahwa pada kolom Collinearity Statistic menunjukkan VIF tidak lebih besar dari 10 dan tolerance lebih dari 0,1 . Berdasarkan hasil tersebut dapat di ketahui bahwa model regresi Substruktural I ini tidak terdapat multikolonieritas, sehingga model dapat dipakai.

\begin{tabular}{lcc}
\hline \multirow{2}{*}{ Variabel } & \multicolumn{2}{c}{ Collinearity Statistics } \\
\cline { 2 - 3 } & Tolerance & VIF \\
\hline $\begin{array}{l}\text { Customer } \\
\text { Satisfaction }\end{array}$ & 0,979 & 1,022 \\
$\begin{array}{l}\text { Perceived } \\
\text { Value }\end{array}$ & 0,967 & 1,035 \\
$\begin{array}{l}\text { Switching } \\
\text { Barrier }\end{array}$ & 0,969 & 1,032 \\
\hline
\end{tabular}

\begin{tabular}{lcc}
\hline \multirow{2}{*}{ Variabel } & \multicolumn{2}{c}{$\begin{array}{c}\text { Collinearity } \\
\text { Statistics }\end{array}$} \\
\cline { 2 - 3 } & Tolerance & VIF \\
\hline $\begin{array}{l}\text { Customer } \\
\text { Satisfaction }\end{array}$ & 0,986 & 1,014 \\
$\begin{array}{l}\text { Perceived } \\
\text { Value }\end{array}$ & 0,986 & 1,014 \\
\hline
\end{tabular}

Berdasarkan tabel IV-12 diatas, diketahui bahwa pada kolom Collinearity Statistic menunjukkan VIF tidak lebih besar dari 10 dan tolerance lebih dari 0,1 . Berdasarkan hasil tersebut dapat di ketahui bahwa model regresi substruktural II ini tidak terdapat multikolonieritas, sehingga model dapat di pakai .

\section{Uji Heterokedastisistas}

Uji Heterokedastisias Sub I

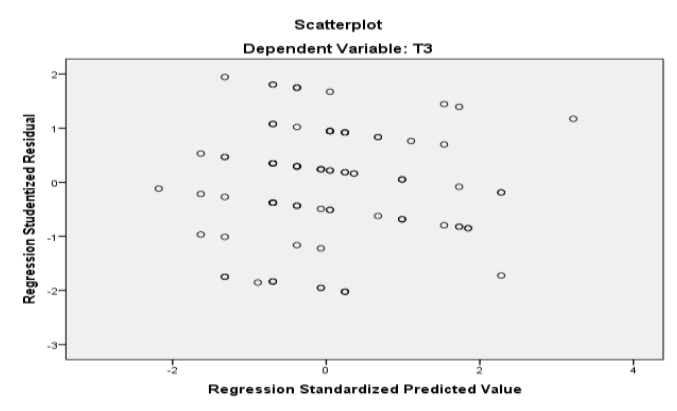


Berdasarkan gambar IV - 3 yaitu grafik dari hasil uji heterokedastisitas yang telah di lakukan, menunjukkan bahwa tidak ada pola tertentu, seperti titik - titik (poin) yang membentuk suatu pola tertentu yang teratur (bergelombang, melebar, kemudian menyempit) dan tidak ada pola yang jelas, maka dapat di simpulkan model regresi dalam penelitian ini tidak terjadi heterokedastisitas.

\section{Uji Heterokedastisitas Sub II}

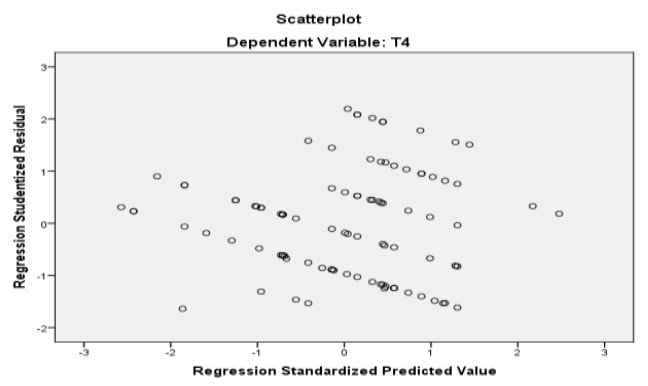

Berdasarkan gambar IV- 4 diatas, dapat diketahui bahwa ada pola tertentu, seperti titik - titik ( poin ) yang membentuk suatu pola tertentu yang teratur ( bergelombang, melebar, kemudian menyempit ) da tidak ada pola yang jelas, maka dapat di simpulkan model regresi dalam penelitian ini tidak terjadi heterokedastisitas.

\section{Uji Normalitas}

\section{Uji Normalitas Sub I}

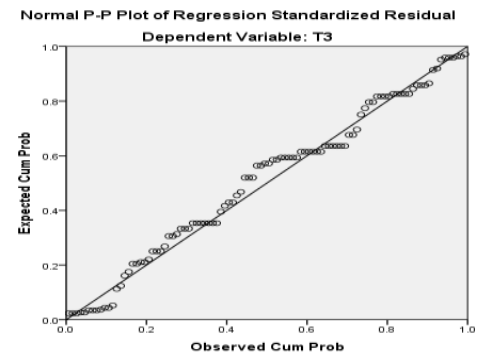

Berdasarkan gambar IV- 1 diatas, bahwa data menyebar di sekitar garis diagonal dan mengikuti arah garis diagonal. Maka model memenuhi asumsi normalitas.
Uji Normalitas Sub II

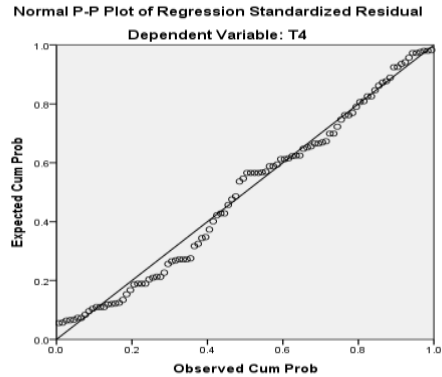

Berdasarkan gambar IV- 2 diatas, bahwa data menyebar di sekitar garis diagonal dan mengikuti arah garis diagonal. Maka model memenuhi asumsi normalitas.

\section{Uji Parsial / Uji t}

\section{Sub I}

\begin{tabular}{|c|c|c|c|c|c|}
\hline \multirow[b]{2}{*}{ Model } & \multicolumn{2}{|c|}{$\begin{array}{l}\text { Unstandardized } \\
\text { Coefficients }\end{array}$} & \multirow{2}{*}{$\frac{\begin{array}{c}\text { Standardized } \\
\text { Coefficients }\end{array}}{\text { Beta }}$} & \multirow[t]{2}{*}{$t$} & \multirow[t]{2}{*}{ Sig. } \\
\hline & B & Std. Error & & & \\
\hline $\begin{array}{ll}\text { (Constant) } \\
\text { (a) }\end{array}$ & 6.655 & 1.746 & & 3.811 & .000 \\
\hline $\begin{array}{l}\text { CUSTOMER } \\
\text { SATISFACTION }\end{array}$ & .076 & .088 & .088 & .871 & .386 \\
\hline PERCEIVED VALUE & .182 & .128 & .142 & 1.415 & .160 \\
\hline
\end{tabular}

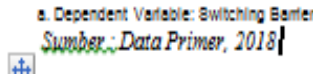

1.)Hubungan customer satisfaction dan switching barriers

Hasil uji $t$ pada tabel IV - 13, menunjukkan nilai $t$ hitung sebesar $0,871<1.98447$ dengan tingkat signifikansi sebesar $0,386>0,05$, sehingga dapat di katakan bahwa customer satisfaction tidak berpengaruh terhadap switching barriers dan $\mathrm{H} 0$ di terima sedangkan $\mathrm{H} 1$ di tolak.

2.) Hubungan antara perceived value dan switching barriers

Hasil uji $\mathrm{t}$ pada tabel IV -13 , menunjukkan nilai $\mathrm{t}$ hitung sebesar $1,415<1,98447$, sehingga tingkat singnifikansi sebesar $0,160>0,05$, sehingga dapat di katakan bahwa perceived value tidak berpengaruh terhadap switching barriers dan $\mathrm{HO}$ di terima sedangkan $\mathrm{H} 1$ di tolak. 
Sub II

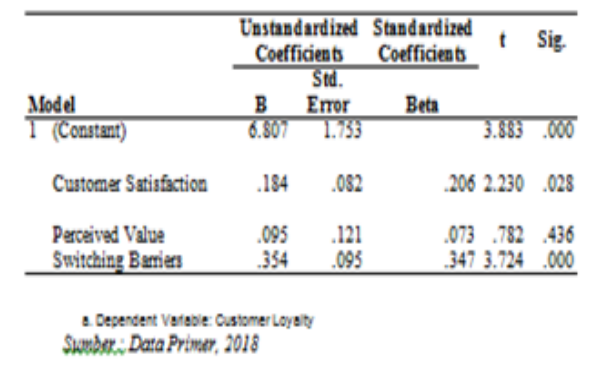

1.)Hubungan Customer Satisfaction dan Customer Loyalty

Hasil uji $t$ pada tabel IV - 14, menunjukkan nilai t hitung sebesar 2,230 $>$ 1,98472 dengan tingkat signifikansi sebesar $0,028<0,05$, sehingga dapat dikatakan bahwa customer satisfaction berpengaruh secara signifikan terhadap customer loyalty dan H0 ditolak sedangkan $\mathrm{H} 1$ di terima.

2.) Hubungan perceived value dan customer loyalty

Hasil uji $t$ pada tabel IV - 14, menunjukkan nilai $\mathrm{t}$ hitung sebesar $0,782<1,98472$ dengan tingkat signifikansi sebesar $0,436>0,05$, sehingga dapat di katakan bahwa perceived value tidak berpengaruh terhadap customer loyalty dan $\mathrm{H} 0$ di terima sedangkan $\mathrm{H} 1$ di tolak.

3.)Hubungan switching barriers dan customer loyalty

Hasil uji $t$ pada tabel IV -14 , menunjukkan nilai t hitung sebesar 3,724 $>1,98472$ dengan tingkat signifikansi sebesar $0,000<0,05$, sehingga dapat di katakan bahwa switching barriers berpengaruh terhadap customer loyalty dan $\mathrm{H} 0$ di tolak sedangkan $\mathrm{H} 1$ di terima.

\section{Koefisien Determinasi}

Sub I

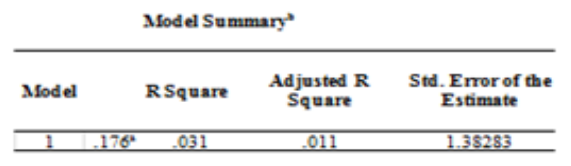

Swubler; Data Primer, 2018

\begin{tabular}{llll}
\hline & & X1 & X2 \\
\hline $\mathbf{X 1}$ & Pearson & 1 & .116 \\
& Correlation & 1 & .249 \\
& Sig. (2-tailed) & .000 & .24 \\
& N & 93 & 93 \\
X2 & Pearson & .116 & 1 \\
& Correlation & .10 & \\
& Sig. (2-tailed) & .249 & .000 \\
& N & 100 & 100 \\
\hline
\end{tabular}

Berdasarkan tabel IV- 15 di atas, besarnya $\mathrm{R}^{2}$ adalah 0,031 hal ini berarti $3,1 \%$ switching barriers dapat di jelaskan oleh Customer satisfaction dan perceived value. Sedangkan sisanya $(100 \%-3,1 \%=96,9 \%)$ di jelaskan oleh sebab - sebab lain di luar model. Standart error of the Estimate ( SEE ) sebesar 1.38283. Semakin kecil SEE akan membuat model regresi semakin tepat dalam memprediksi variabel dependen.

Sub II

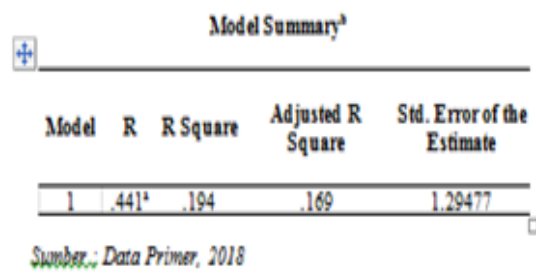

Berdasarkan tabel IV -16 di atas besar $\mathrm{R}^{2}$ adalah 0,169 hal ini berarti $16,9 \%$ customer loyalty dapat di jelaskan oleh customer satisfaction, perceived value dan switching barriers. Sedangkan sisanya ( $100 \%-16,9 \%=83,1 \%$ ) dijelaskan oleh sebab - sebab lain di luar model. Standart error of the Estimate ( SEE ) sebesar 1,29477. Makin kecil SEE akan membuat model regresi semakin tepat dalam mempredikasi variabel dependen.

\section{Analisis Korelasi}

Berdasarkan Tabel IV-17 hasil uji korelasi antar variabel di atas menunjukkan bahwa korelasi antar variabel customer satisfaction (X1) dan variabel perceived value (X2) memiliki korelasi sangat lemah, dengan angka sebesar 0,116. Kedua variabel tersebut memiliki angka signifikansi sebesar $0,249>0,05$ yang dapat di artkan bahwa kedua variabel tersebut tidak signifikan. 
Analisis Jalur

Sub I

\begin{tabular}{ccc}
\hline No & Notasi & $\begin{array}{c}\text { Koefisien } \\
\text { Regresi }\end{array}$ \\
\hline 1. & $\mathrm{P} 1$ & 0,088 \\
2. & $\mathrm{P} 2$ & 0,142 \\
3. & $€ 1$ & 0,9843 \\
\hline \multicolumn{2}{l}{ Y1 $=0,088 \mathrm{X} 1+0,142 \mathrm{X} 2+€_{1}$}
\end{tabular}

Kemudian nilai-nilai P1, P2 dan $€ 1$, di jelaskan sebagai berikut :

1. Variabel Independen

a. Koefisien regresi variabel Customer satisfaction $(\mathrm{P} 1)=0,088$.

Koefisien regresi untuk X1 sebesar 0,088 artinya setiap penambahan 1 skala likert pada variabel customer satisfaction ( $\mathrm{X} 1$ ), maka akan menambah tingkat switching barriers sebesar 0,088.

2. Koefisien regresi variabel perceived value $(\mathrm{P} 2)=0,142$.

Koefisien regresi untuk X2 sebesar 0,142 artinya setiap penambahan 1 skala likert pada variabel perceived value ( X2 ), maka akan menambah tingkat switching barriers sebesar 0,142 .

\section{Eror $(€ 1)$}

Eror $(€ 1)$ sebesar 0,9843 menunjukkan switching barriers yang tidak dapat di jelaskan oleh variabel customer satisfaction (X1) dan perceived value (X2), diabaikan atau sama dengan nol.

Sub II

\begin{tabular}{ccc}
\hline No & Notasi & $\begin{array}{c}\text { Koefisien } \\
\text { Regresi }\end{array}$ \\
\hline 1. & P1 & 0,206 \\
2. & P2 & 0,073 \\
3. & P3 & 0,347 \\
4. & $€ 2$ & 0,8977 \\
\hline Y2 $=0,206 \mathrm{X} 1+0,073 \mathrm{X} 2+0,347 \mathrm{Y} 1+€ 2$
\end{tabular}

Kemudian nilai - nilai P1, P2, P3 dan €2 di jelaskan sebagai berikut :

1. Variabel Independen

a. Koefisien regresi variabel cutomer satisfaction $(P 1)=0,206$

Koefisien regresi untuk X1 sebesar 0,206 artinya setiap penambahan 1 satuan skala likert pada variabel customer satisfaction ( X1 ), maka akan menambah customer satisfaction sebesar 0,206.

b. Koefisien regresi variabel perceived value $(\mathrm{X} 2)=0,073$

Koefisien regresi untuk X2 sebesar 0,073 artinya setiap penambahan 1 satuan skala likert pada variabel perceived value ( X2 ), maka akan menambah customer loyalty sebesar 0,073.

c. Koefisien regresi variabel switching barriers ( Y1 ) $=0,347$

Koefisien regresi untuk Y1 sebesar 0,347 artinya setiap penambahan skala likert variabel switching barriers ( Y1 ), maka akan menambah customer loyalty sebesar 0,347

2. Eror $(€ 1)$

Eror $\quad(€ 1) \quad$ sebesar $\quad 0,8977$ menunjukkan customer loyalty yang tidak dapat di jelaskan oleh variabel customer satisfaction ( X1), perceived value ( X2) dan switching barrier (Y1) diabaikan atau sama dengan nol.

\section{Diagram Jalur}

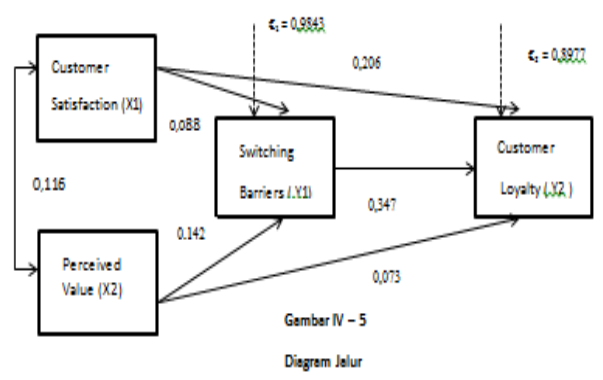

a. Pengaruh Langsung (Direct Effect atau DE)

1. Pengaruh variabel customer satisfaction terhadap switching barriers

$\mathrm{X} 1 \longrightarrow \mathrm{Y}=0,088$ 
2. Pengaruh variabel perceived value terhadap switching barriers

$\mathrm{X} 2 \longrightarrow 1=0,142$

3. Pengaruh variabel customer satisfaction terhadap customer loyalty

$\mathrm{X} 1 \longrightarrow \mathrm{Y} 2=0,206$

4. Pengaruh variabel customer satisfaction terhadap customer loyalty

$\mathrm{X} 2 \longrightarrow \mathrm{Y} 2=0,073$

5. Pegaruh switching barriers terhadap customer loyalty

$\mathrm{Y} 1 \longrightarrow \mathrm{Y} 2=0,347$

b. Pengaruh tidak langsung (Indirect Effect atau IE)

1. Pengaruh variabel customer satisfaction terhadap customer loyalty melalui switching barriers $\mathrm{X} 1 \longrightarrow \mathrm{Y} 1 \longrightarrow \mathrm{Y} 2=(0,088$ $\mathrm{x} 0,347)=0,030536$

2. Pengaruh variabel perceived value terhadap customer loyalty melalui switching barriers

$\mathrm{X} 2 \longrightarrow \mathrm{Y} 1 \longrightarrow 2=(0,142 \mathrm{x}$ $0,347)=0,049274$

c. Pengaruh Total (Total Effect)

1. Pengaruh variabel customer satisfaction terhadap customer satisfaction melalui switching barriers

$\mathrm{X} 1 \longrightarrow \mathrm{Y} 2 \Rightarrow 0,088 \times 0,347$ ) $=0,030536$

2. Pengaruh variabel peceived value terhadap customer loyalty melalui switching barriers

$\mathrm{X} 2 \longrightarrow \mathrm{Y} 2=(\mathbb{1}, 142 \times 0,347$ ) $=0,049274$

3. Pengaruh variabel customer satisfaction terhadap customer loyalty

$\mathrm{X} 1 \longrightarrow 2=0,206$
4. Pengaruh variabel perceived value terhadap customer loyalty $\mathrm{X} 2-\mathrm{Y}=0,073$

5. Pegaruh variabel switching barriers terhadap customer loyalty

$\mathrm{Y} 1 \longrightarrow \mathrm{Y}=0,347$

\section{Implikasi Manajerial}

Penelitian ini bertujuan untuk mengetahui seberapa besar pengaruh customer satisfaction dan perceived value terhadap switching barrier dan customer loyalty.

Implikasi yang disarankan dalam penelitian ini adalah sebagai berikut :

1. Pengaruh Customer Satisfaction terhadap Switching Barriers Pengujian hipotesis pertama dilakukan untuk mengetahui pengaruh customer satisfaction terhadap switching bariers. Berdasarkan hasil uji $\mathrm{t}$ diperoleh nilai 0.088 atau $8,8 \%$ dengan taraf signifikansi $0,386>0,05$. Kondisi ini menunjukkan bahwa customer satisfaction tidak memberikan pengaruh yang signifikan terhadap switching barriers.

Selanjutnya penelitian ini sejalan dengan hasil penelitian yang dilakukan oleh $\mathrm{Ni}$ Luh W tahun 2014 dengan judul "Kepuasan Pelanggan Terhadap Citra Perusahaan Dan Switching Barriers Serta Dampaknya Terhadap Loyalitas Pelanggan Industri Jasa Asuransi Di Bali". Hasil penelitian ini yaitu customer satisfaction tidak berpengaruh terhadap switching barriers.

2. Pengaruh Perceived Value terhadap Switching Barriers

Pengujian hipotesis kedua dilakukan untuk mengetahui pengaruh perceived value terhadap switching barriers. Berdasarkan hasil uji t diperoleh nilai 0,142 atau $14,2 \%$ dengan taraf signifikansi $0,160>0,05$. Kondisi saat ini menunjukkan bahwa perceived value tidak memberikan pengaruh yang 
signifikan terhadap switching barriers.

Dalam hal ini sebaiknya meningkatkan persepsi nilai produknya dengan cara memberikan kualitas produk yang sesuai dengan apa yang telah konsumen berikan, seperti harga yang lebih tinggi dibandingkan dengan bakery lainnya maka dari kualitas produk roti yang dihasilkan oleh Banana Bakerypun tentunya harus sesuai dengan harga yang dimana memiliki keunggulan kualitas yang lebih baik dibandingkan dengan bakery lainnya.

Khotler,Philip.2009.Manajemen pemasaran. Jakarta.Erlangga.

3.Pengaruh Customer Satisfaction terhadap Customer Loyalty

Pengujian hipotesis ketiga dilakukan untuk mengetahui pengaruh customer satisfaction tehadap customer loyalty. Berdasarkan hasil uji t di peroleh nilai 0,206 atau $20,6 \%$ dengan taraf signifikansi $0,028<0,05$. Kondisi seperti ini menyatakan bahwa customer satisfaction memberikan pengaruh yang signifikan terhadap customer loyalty. Berdasarkan hasil uji tersebut maka Banana Bakery Kebumen tetap harus mempertahankan dan menjaga kualitas produk rotinya sehingga menyebabkan konsumen loyal.

Selanjutnya penelitian ini sejalan dengan hasil penelitian yang dilakukan oleh Yenny tahun 2014 dengan judul "Pengaruh Kepuasan, Hambatan Berpindah Dan Penyediaan Fasilitas Terhadap Loyalitas Konsumen Di Hotel Novotel Surabaya". Hasil penelitian ini yaitu customer satisfaction berpengaruh terhadap customer loyalty.

4. Pengaruh Perceived Value terhadap Customer Loyalty

Pengujian hipotesis ke empat dilakukan untuk mengetahui pengaruh perceived value terhadap customer loyalty. Bedasarkan hasil uji $\mathrm{t}$ di peroleh nilai 0,206 atau $20,6 \%$ dengan taraf signifikansi 0,436>0,05. Kondisi seperti ini menyatakan bahwa perceived value tidak memberikan pengaruh yang signifikan.

Selanjutnya penelitian ini sejalan dengan hasil penelitian yang dilakukan oleh Gantra 2013 dengan judul "Analisis Pengaruh Kualitas Layanan Dan Perceived Value Terhadap Kepuasan Pelanggan Dan Loyalitas Pelanggan”. Hasil penelitian ini yaitu perceived value tidak berpengaruh terhadap customer loyalty.

5. Pengaruh Switching Barriers terhadap Customer Loyalty

Pengujian hipotesis ke lima di lakukan untuk mengetahui pengaruh switching barriers terhadap customer loyalty . Berdasarkan hasil uji $\mathrm{t}$ di peroleh nilai 0,347 atau $34,7 \%$ dengan taraf signifikansi $0,000<0,05$.Kondisi ini menunjukkan bahwa switching barrier memberikan pengaruh yang signifikan terhadap customer loyalty.

Selanjutnya penelitian ini sejalan dengan hasil penelitian yang dilakukan oleh Chung 2011 dengan judul "The Effects Of Relationship Quality And Switching Barriers On Customer Loyalty". Hasil penelitian ini yaitu switching barriers berpengaruh terhadap customer loyalty.

\section{Kesimpulan}

Berdasarkan hasil analisis data yang terkumpul dari kuesioner mengenai Customer Satisfaction (X1), Perceived Value (X2) terhadap Switching Barrier (Y1) dan Customer Loyalty (Y2) pada Konsumen Banana Bakery Kebumen didapat kesimpulan sebagai berikut :

1. Responden pada Banana Bakery Kebumen didominasi oleh perempuan.

2. Hasil penelitian ini menunjukkan bahwa variabel customer satisfaction tidak berpengaruh signifikan terhadap switching barriers pada konsumen Banana Bakery Kebumen. 
Artinya walaupun kepuasan konsumen akan produk di Banana Bakery Kebumen cukup baik tidak memiliki pengaruh terhadap switching barriers ketika konsumen membeli dan mengonsumsi roti Banana Bakery Kebumen.

3. Hasil penelitian ini menunjukkan bahwa variabel perceived value tidak berpengaruh signifikan terhadap switching barriers pada konsumen Banana Bakery Kebumen. Artinya walaupun penilaian akan produk roti Banana Bakery Kebumen cukup baik tidak memiliki pengaruh terhadap switching barriers ketika konsumen membeli dan mengonsumsi roti Banana Bakery Kebumen.

4. Hasil penelitian ini menujukkan bahwa variabel customer satisfaction mempunyai pengaruh signifikan terhadap customer loyalty pada konsumen

Banana Bakery Kebumen. Artinya semakin konsumen puas maka konsumen tersebut akan loyal terhadap produk roti Banana Bakery Kebumen.

5. Hasil penelitian ini menunjukkan bahwa variabel perceived value tidak berpengaruh signifikan terhadap customer loyalty pada konsumen Banana Bakery Kebumen. Artinya walaupun persepsi nilai terhadap produk roti Banana Bakery Kebumen cukup tidak memiliki pengaruh terhadap loyalitas konsumen.

6. Hasil penelitian ini menunjukkan pengaruh bahwa variabel switching barriers mempunyai pengaruh signifikan terhadap customer loyalty pada konsumen Banana Bakery Kebumen. Artinya semakin besar hambatan berpindah yang diterapkan oleh Banana Bakery Kebumen maka akan meningkatkan loyalitas konsumen.

\section{Saran}

\section{Bagi Perusahaan}

Berdasarkan

kesimpulan dari hasil yang telah dilakukan, penulis memberi saran sebagai masukan agar dapat meningkatkan loyalitas konsumen melalui switching barriers sebagai variabel intervening pada produk roti Banana Bakery Kebumen :

1. Meningkatkan kualitas produk dari segi rasa, sehingga memungkinkan konsumen untuk enggan berpindah ke produk lain dan konsumen akan tetap loyal terhadap produk roti Banana Bakery Kebumen.

2. Lebih meyakinkan konsumen jika mereka berpindah ke produk lain maka akan membuang waktu.

\section{Bagi Peneliti Selanjutnya}

1. Penelitian ini di lakukan pada konsumen di Banana Bakery Kebumen, untuk penelitian selanjutnya di sarankan untuk melakukan penelitian pula pada konsumen di cabang Banana Bakery di Purwokerto, agar jangkauan responden lebih luas serta agar penelitian ini menjadi lebih baik.

2. Penelitian ini mengangkat pengaruh customer satisfaction dan perceived 
value terhadap switching barriers dan customer loyalty , studi pada Konsumen Banana Bakery Kebumen. Variabel yang di gunakan penelitian selanjutnya bisa menggunakan variabel yang sama atau dengan menambahkan variabel lain.

\section{Penelitian}

Penelitian ini hanya
dibatasi pada variabel
customer satisfaction,
perceived value, switching
barriers dan customer loyalty
dan hanya di lakukan pada
konsumen Banana Bakery
Kebumen.

\section{DAFTAR PUSTAKA}

Gantra , Gery., Kumadji, Srikandi, dan Yuliato, Edy. 2013. Analisis Pengaruh Kualitas Layanan Dan Perceived Value Terhadap Kepuasan Pelanggan Dan Loyalitas Pelanggan. Jurnal Administrasi Binis Vol.1 No. 1

Ghozali, Imam. 2006. Aplikasi Analisis Multivariate Dengan Program SPSS. Semarang : Universitas Diponegoro.

Ghozali, Imam. 2009. Ekonometrika Teori Konsep Dan Aplikasi Dengan SPSS 17. Semarang: Universitas Diponegoro.

Ghozali, Imam. 2013. Aplikasi Analisis Multivariate Dengan Program Ibm Spss 21 Update Pls Regresi. Semarang : Universitas Diponegoro.

Ghozali, Imam. 2016. Aplikasi Analisis Multivariate Dengan Program IBM SPSS 23. Semarang: Universitas Diponegoro.

Khotler,Philip. 2009. Manajemen Pemasaran. Jakarta. Erlangga.

Liu, T. C., Guo, M .Y, dan Lee, H.C. 2011. The Effects Of Relationship Quality And Switching Barriers On Customer
Loyalt. .International Journal of Information Management 31.

Puspita, Indah Annisa ., Abdillah , Yusri, dan Bafadhal, Samira Aniesa . 2018. Pengaruh Customer Satisfaction Terhadap Switching Barriers Dan Customer Retention. Jurnal Administrasi Bisnis Vol. 61 No. 1.

Qonitat, Niswahtun Nira., Suyadi ,Imam, dan Sunarti. 2018. Pengaruh Kepuasan Pelanggan, Switching Barrier Dan Kepercayaan Merek Terhadap Customer Retention. Jurnal Administrasi Bisnis Vol.55 No.2.

Rahab., Handayani, Retno Sri., Nawarini, Tri Alisa. 2015. Peran Perceived Value Dan Kepuasan Pelanggan Dalam Upaya Membangun Loyalitas Pengguna Kartu Seluler. Jurnal Media Ekonomi dan Manajemen Vol. 30 No. 1.

S , Yenny Chen., Japarianto, Edwin. 2014. Pengaruh Kepuasan, Hambatan Berpindah Dan Penyediaan Fasilitas Terhadap Loyalitas Konsumen Di Hotel Novotel Surabaya. Jurnal Strategi Pemasaran Vol. 2 No. 1.

Sarwono, Jonathan. 2007. Analisis Jalur Untuk Riset Bisnis dengan SPSS. Yogyakarta : Andi Offset.

Sugiyono.2009.Metode Penelitian Bisnis ( Pendekatan Kuantitatif, Kualitatif dan $R \& D$ ). Bandung. Alfabeta.

Sugiyono.2010. Metode Penelitian Bisnis.Cetakan ke-15. Bandung. Alfabeta.

Sutrisno, Hadi . 2004. Metodology Research Jilid 3. Yogyakarta : Andi.

Telagawathi, Sayang dan Reonningrat, Putu Luh. 2014. Kepuasan Pelanggan Terhadap Citra Perusahaan Dan Switching Barriers Serta Dampaknya Terhadap Loyalitas Pelanggan Industry Jasa Asuransi Di Bali. Jurnal Manajemen \& Akuntansi STIE Triatma Mulya Vol. 20 No. 2. 